Article

\title{
Blue-Sky Albedo Reduction and Associated Influencing Factors of Stable Land Cover Types in the Middle-High Latitudes of the Northern Hemisphere during 1982-2015
}

\author{
Saisai Yuan ${ }^{1,2}$, Yeqiao Wang ${ }^{3}$, Hongyan Zhang ${ }^{1,2, *}$, Jianjun Zhao ${ }^{1,2} \mathbb{D}$, Xiaoyi Guo ${ }^{1,2} \mathbb{D}$, Tao Xiong $^{1,2}$ (D), \\ Hui $\mathrm{Li}^{1,2}$ and Hang Zhao ${ }^{1,2}$
}

Citation: Yuan, S.; Wang, Y.; Zhang, H.; Zhao, J.; Guo, X.; Xiong, T.; Li, H.; Zhao, H. Blue-Sky Albedo Reduction and Associated Influencing Factors of Stable Land Cover Types in the Middle-High Latitudes of the Northern Hemisphere during 1982-2015. Remote Sens. 2022, 14, 895 https://doi.org/10.3390/rs14040895

Academic Editors: Maria Lanfredi, Rosa Coluzzi, Vito Imbrenda Tiziana Simoniello and Yi Luo

Received: 13 December 2021 Accepted: 11 February 2022 Published: 13 February 2022

Publisher's Note: MDPI stays neutral with regard to jurisdictional claims in published maps and institutional affiliations.

Copyright: (c) 2022 by the authors Licensee MDPI, Basel, Switzerland. This article is an open access article distributed under the terms and conditions of the Creative Commons Attribution (CC BY) license (https:// creativecommons.org/licenses/by/ $4.0 /)$.
1 Key Laboratory of Geographical Processes and Ecological Security in Changbai Mountains, Ministry of Education, School of Geographical Sciences, Northeast Normal University, Changchun 130024, China; yuanss592@nenu.edu.cn (S.Y.); zhaojj662@nenu.edu.cn (J.Z.); guoxy914@nenu.edu.cn (X.G.); xiongt830@nenu.edu.cn (T.X.); lih795@nenu.edu.cn (H.L.); zhaoh648@nenu.edu.cn (H.Z.)

2 Urban Remote Sensing Application Innovation Center, School of Geographical Sciences, Northeast Normal University, Changchun 130024, China

3 Department of Natural Resources Science, University of Rhode Island, Kingston, RI 02881, USA; yqwang@uri.edu

* Correspondence: zhy@nenu.edu.cn; Tel.: +86-188-4319-4798

\begin{abstract}
Land surface albedo (LSA) directly affects the radiation balance and the surface heat budget. LSA is a key variable for local and global climate research. The complexity of LSA variations and the driving factors highlight the importance of continuous spatial and temporal monitoring. Snow, vegetation and soil are the main underlying surface factors affecting LSA dynamics. In this study, we combined Global Land Surface Satellite (GLASS) products and ERA5 reanalysis products to analyze the spatiotemporal variation and drivers of annual mean blue-sky albedo for stable land cover types in the middle-high latitudes of the Northern Hemisphere $\left(30 \sim 90^{\circ} \mathrm{N}\right)$ from 1982 to 2015 . Snow cover (SC) exhibited a decreasing trend in $99.59 \%$ of all pixels (23.73\% significant), with a rate of -0.0813 . Soil moisture (SM) exhibited a decreasing trend in $85.66 \%$ of all pixels (22.27\% significant), with a rate of -0.0002 . The leaf area index (LAI) exhibited a greening trend in $74.38 \%$ of all pixels $(25.23 \%$ significant), with a rate of 0.0014 . Blue-sky albedo exhibited a decreasing trend in $98.97 \%$ of all pixels (65.12\% significant), with a rate of -0.0008 (OLS slope). Approximately $98.16 \%$ of all pixels $(57.01 \%$ significant) exhibited a positive correlation between blue-sky albedo and SC. Approximately $47.78 \%$ and $67.38 \%$ of all pixels (17.13\% and $25.3 \%$ significant, respectively) exhibited a negative correlation between blue-sky albedo and SM and LAI, respectively. Approximately 10.31\%, 20.81\% and 68.88\% of the pixel blue-sky albedo reduction was mainly controlled by SC, SM and LAI, respectively. The decrease in blue-sky albedo north of $40^{\circ} \mathrm{N}$ was mainly caused by the decrease in SC. The decrease in blue-sky albedo south of $40^{\circ} \mathrm{N}$ was mainly caused by SM reduction and vegetation greening. The decrease in blue-sky albedo in the western Tibetan Plateau was caused by vegetation greening, SM increase and SC reduction. The results have important scientific significance for the study of surface processes and global climate change.
\end{abstract}

Keywords: blue-sky albedo; spatiotemporal variation; snow cover; soil moisture; LAI

\section{Introduction}

Land surface albedo (LSA), a variable defined as the fraction of incident solar radiation reflected by the land surface, exerts significant effects on the land surface radiation budget and climate change [1,2]. LSA responds to and interacts with climate variability through various mechanisms. According to the Intergovernmental Panel on Climate Change (IPCC) report, the increased LSA caused by anthropogenic land use changes has led to a global cooling effect that is as high as $-0.15 \mathrm{~W} \mathrm{~m}^{-2}$ [3]. Snow melting or vegetation greening 
causes a decrease in LSA, allows more solar radiation to reach the surface and it increases the surface temperature [4]. In contrast, the significant increase in LSA can affect large-scale atmospheric circulation movements, such as tropical convergence zones and monsoons, resulting in a reduction in precipitation [5], intensification of drought in semiarid areas [6] and expansion of deserts [7]. Considering the dominant position of radiation feedback in climate change, it is necessary to evaluate the long-term LSA variations.

LSA is highly variable, both spatially and temporally. It is subject to the effects of the solar zenith angle [8], underlying surface conditions [9] and climate change [10]. Because of its high reflectivity, snow has a greater effect on the LSA than other factors [11]. During the growing season, the LSA associated with vegetation changes has an important impact on the surface energy budget [4]. Temperature and precipitation can affect the LSA through different mechanisms and subsequently change the available energy on the surface [12]. For example, temperature can affect the particle size of snow [13], snow melting [14] and the phenology of vegetation [15], resulting in variations in LSA. Precipitation can change vegetation greenness and soil moisture (SM), especially in arid areas, causing variations in LSA $[15,16]$. In general, snow, vegetation and SM directly affect LSA through land cover changes and soil, while temperature and precipitation indirectly affect LSA through vegetation growth, snow melting and SM [17].

The Fourth Assessment of the IPCC attributed the intensity of snow albedo feedback to the decrease in albedo caused by the reduction in snow cover (SC) rather than snow metamorphism [14]. Previous studies generally believed that the reduction in snow cover extent and duration in the northern hemisphere (NH) began in the mid-1980s [18,19], with little change was previously reported [18]. Snow albedo feedback was an important driving factor of regional climate change in NH extratropical land, and the peak feedback of LSA decreased by approximately $1 \%$ for every degree of warming in spring [20]. The LSA feedback of the $\mathrm{NH}$ cryosphere was between 0.3 and $1.1 \mathrm{~W} \mathrm{~m}^{-2} \mathrm{~K}^{-1}$ [21]. A series of satellite-based datasets have unequivocally shown that the land surface has been green for the past 30 years $[15,22,23]$. The greening rate of the northern temperate region $\left(25 \sim 50^{\circ} \mathrm{N}\right)$ was higher than that of high northern latitudes $\left(>50^{\circ} \mathrm{N}\right)$ since 2000 [15]. The results of 3 longterm satellite leaf area index (LAI) records and 10 global ecosystem models showed that the LAI in the growing season increased continuously and widely over $25 \%$ to $50 \%$ of the global vegetated area from 1982 to 2009 [23]. Vegetation greening can produce either positive or negative feedback in different regions and seasons, depending on whether the underlying surface to be replaced has a higher albedo (such as snow) or lower albedo (such as dark soil) than vegetation [9]. In snow-covered regions, the snow-masking effect of vegetation can significantly decrease LSA [11]. In most NH forest regions, organic soils are darker than vegetation, and vegetation greening can produce negative feedback [9]. Over the past half century, most regions of the world have shown a significant drying trend [24-26]. $\mathrm{SM}$ reduction contributes to an increase in soil albedo and a decrease in net radiation, which in turn leads to a decrease in atmospheric convergence rise, convective clouds and precipitation. These soil albedo feedbacks can drive "drought intensification" [27-29]. Moreover, previous studies based on observational and reanalysis data have shown that SM drying has an important effect on heat waves and extremely high temperatures in large-scale areas $[25,27]$.

There was a stable seasonal snow mass in the non-alpine regions above $40^{\circ} \mathrm{N}$ from 1980 to 2018 [30]. The extent and duration of SC in the NH have decreased since the mid-1980s [19].The fastest warming in recent decades occurred in northern mid-latitudes, reaching $0.4 \mathrm{~K}$ in the last decade ${ }^{-1}$ [31]. Many facts reveal that warming has an important impact on global dry and wet changes. Precipitation variability increased with global warming at synoptic, monthly, intraseasonal and interannual time scales, and the enhancement mainly occurred in climatologically wet regions, where precipitation climatology exceeded $50 \%$ of the global average [5]. The global dryland areas increased at a rate of $512,180 \mathrm{~km}^{2}$ decade $^{-1}$ from 1948 to 2009. Except for North America, the five continents in the world were becoming drier, while North America was becoming wetter [32]. In 
addition, climate warming led to the general advancement of the vegetation green-up date in the middle-high latitudes of the $\mathrm{NH}$, and the advanced green-up dates in temperate and boreal forests had obvious warming effects on the middle-high latitudes of the NH [33]. The complex underlying surfaces in the middle-high latitudes of the NH exert enormous impacts on LSA variation.

From 2000 to 2008, the variation in LSA based on MODIS showed that the LSA of NH decreased by 0.01 [34]. From 2002 to 2016, the LSA in the high latitudes of the NH decreased by 0.013 , while the LSA in the low latitudes did not fluctuate significantly [4]. Assessments based on nine global-scale satellite albedo datasets from 1981 to 2010 have shown that LSA over the NH decreased in July and increased in January [8]. Satellite product albedo studies mostly use black-sky albedo or white-sky albedo, while the time scale of blue-sky albedo is only over 10 years. When calculating the blue-sky albedo, the diffuse sky light ratio is ignored or assumed to be constant. Therefore, the long-term variations in blue-sky albedo still need to be determined. Previous studies have found good correlations between LSA and vegetation or snow in the NH, but it is not clear how snow, vegetation and SM affect the LSA through competing effects. In particular, the regional trends and drivers of LSA variations may vary depending on the spatial and temporal resolutions of the specific analysis. Thus, we used Global Land Surface Satellite (GLASS) products and ERA5 reanalysis data to estimate the spatiotemporal variation in stable land cover types of blue-sky albedo in the middle-high latitudes of the NH from 1982 to 2015; then, we quantify the correlation between blue-sky albedo and relevant influencing factors (SC, SM and LAI), clarify the main drivers of blue-sky albedo variation and improve the understanding of climate and ecological environment changes in the middle-high latitudes of the NH.

\section{Materials and Methods}

\subsection{Data and Preprocessing}

\subsubsection{GLASS Products}

The GLASS products were generated and released by the Center for Global Change Data Processing and Analysis of Beijing Normal University [35]. These products provide consistent AVHRR datasets at $0.05^{\circ}$ and 8 day resolutions from 1981 to present (http: / / glass.umd.edu/Download.html, accessed on 12 December 2021).

Compared with other global LSA products, the GLASS AVHRR albedo product has a higher spatial and temporal resolution, as well as a longer time span. The GLASS AVHRR albedo product was evaluated by ground measurement and MODIS albedo products [36,37]. The black-sky albedo and white-sky albedo indicate the directionalhemispherical reflectance and bi-hemispherical reflectance, respectively, which are provided in the GLASS AVHRR albedo products. The blue-sky albedo represents the true albedo of surface features and is a linear weighting between black-sky albedo and white-sky albedo [38]. The blue-sky albedo was calculated as follows:

$$
X=(1-s) \times \alpha_{b s}+s \times \alpha_{w s}
$$

where $X$ is the blue-sky albedo, $s$ is the diffuse skylight ratio, $\alpha_{b s}$ is the black-sky albedo and $\alpha_{w s}$ is the white-sky albedo [38].

Compared with other vegetation spectral indices, the LAI can provide more-accurate information about vegetation dynamics [23]. Moreover, previous studies have evaluated four long-term series global LAI products, and the results have shown that the GLASS AVHRR LAI product was spatially complete, which reasonably represented the global vegetation characteristics and their seasonal variability. The GLASS AVHRR LAI values showed better performances than other products [39].

First, the invalid data were removed by using the quality assessment subdatasets. Then, all AVHRR products were reprojected to the WGS84 coordinate system. However, zenithal projection was uniformly used in mapping. 


\subsubsection{GLASS-GLC Product}

The land cover data used in this study were from the GLASS-GLC (Global Land Cover) product (https:/ / doi.pangaea.de/10.1594/PANGAEA.913496, accessed on 12 December 2021), which is the first record of 34 year-long annual dynamics of global land cover spanning from 1982 to 2015 at a $5 \mathrm{~km}$ resolution. The average overall accuracy for the 34 years, each with 7 classes, including cropland, forest, grassland, shrubland, tundra, barren land and snow /ice, is $82.81 \%$ based on 2431 test sample units [40].

The GLASS-GLC dataset was preprocessed by reclassification and raster calculation, and the 34 year land cover type invariant areas were extracted as the study area (Figure 1a). Shrublands in this study were not included because of their small number of invariant areas. The land cover types in the study area have changed substantially in the past 34 years. Only $35.31 \%$ of the cropland, $65.31 \%$ of the forest, $36.52 \%$ of the grassland, $59.09 \%$ of the tundra, $63.18 \%$ of the barren land and $81.76 \%$ of the snow/ice have not changed compared with 1982 (Figure 1b).

a

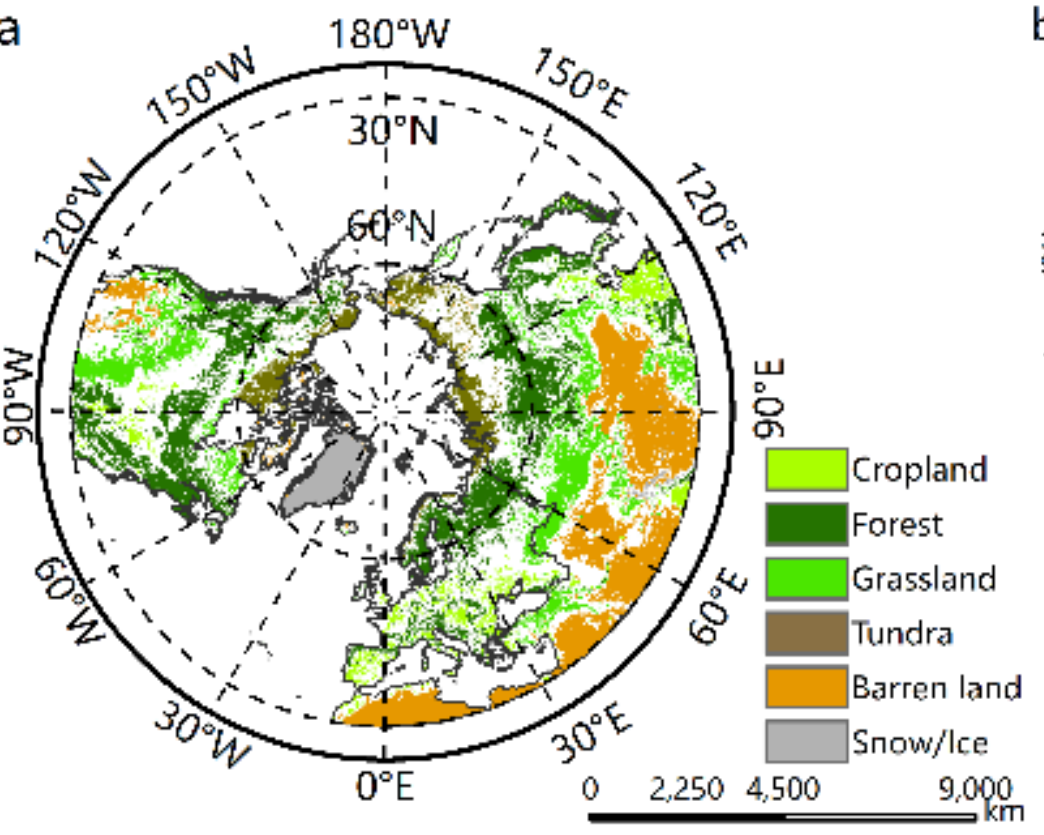

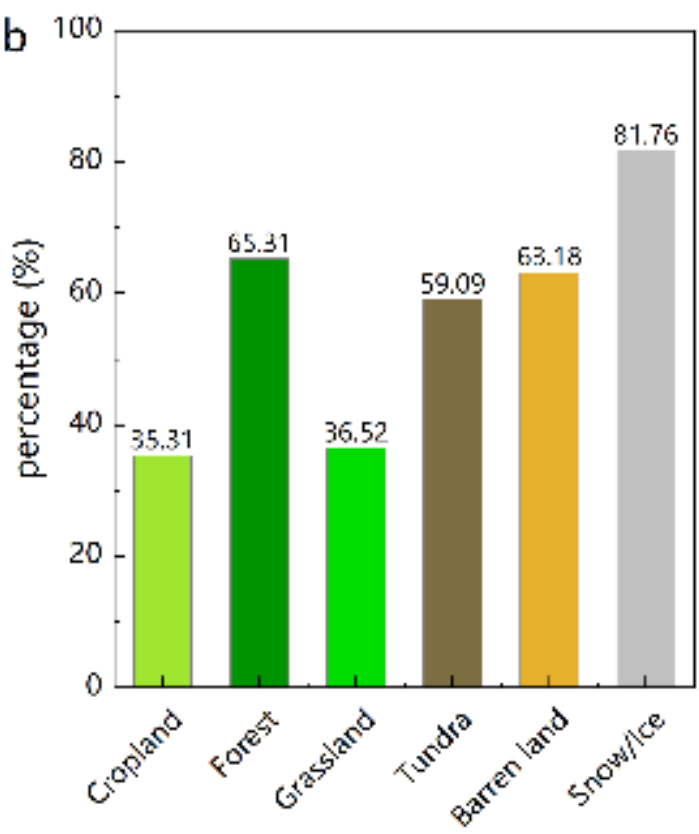

Figure 1. Spatial distribution and statistics of the study area. (a) Spatial distribution of stable (unchanged) land cover types in the period 1985-2015; changed regions are shown in white. (b) Percentage of stable land cover types in the period.

\subsubsection{ERA5 Reanalysis Products}

ERA5 is the fifth generation of reanalysis data from the European Centre for MediumRange Weather Forecasts (ECMWF, https:/ / cds.climate.copernicus.eu/cdsapp\#!/dataset/ reanalysis-era5-single-levels-monthly-means?tab=overview, accessed on 12 December 2021), which provides more accurate hourly data at a spatial resolution of $31 \mathrm{~km}$ compared with the other reanalysis sources [41]. In this study, monthly shortwave radiation and direct solar radiation at a $0.25^{\circ}$ spatial resolution were used to compute the diffuse skylight ratio. Specifically, the diffuse skylight ratio is equal to the diffuse solar radiation divided by the shortwave radiation, and the diffuse solar radiation is equal to the difference between shortwave radiation and direct solar radiation.

ERA5-Land was produced by replaying the land component of the ECMWF ERA5 climate reanalysis, which provides a consistent view of the evolution of land variables over several decades at an enhanced resolution compared to ERA5. It was shown to reasonably capture surface SM annual variability [42]. The monthly SC and SM at a $0.1^{\circ}$ spatial resolution were obtained from ERA5-Land (https: / cds.climate.copernicus.eu/cdsapp\# !/ dataset/reanalysis-era5-land-monthly-means?tab=overview, accessed on 12 December 
2021). The unit of SC is percent per pixel, it represents the fraction (0-1) of the cell/grid-box occupied by snow. The unit of SM is $\mathrm{m}^{3} \mathrm{~m}^{-3}$, which refers to the ratio of the volume occupied by water in the soil to the total volume of the soil, including $0 \sim 7 \mathrm{~cm}, 7 \sim 28 \mathrm{~cm}$, $28 \sim 100 \mathrm{~cm}$ and $100 \sim 289 \mathrm{~cm}$. In the average global root profile, approximately $75 \%$ of the roots were distributed in the top $40 \mathrm{~cm}$ of the soil [43], and the $5 \mathrm{~cm}$ depth of SM collected SM information from $0 \sim 60 \mathrm{~cm}$, which was suitable for drought monitoring applications [44]. In this study, an SM of $0 \sim 7 \mathrm{~cm}$ was selected to reveal the soil drought status.

To match the GLASS products, these two datasets were resampled to $0.05^{\circ}$ by using the nearest-neighbor resampling method. The nearest-neighbor sampling is suitable for continuous data and land-use classification.

\subsection{Statistical Analysis Methods}

\subsubsection{Trend Analysis}

The Mann-Kendall (M-K) test is a nonparametric method that was used to detect the change trend of blue-sky albedo at the pixel scale. The M-K test does not require the independence and normality of the time series data because it is not sensitive to some outliers. Therefore, it has a wide detection range and high trend detection technology [45]. The Theil-Sen (TS) median slope estimator was applied to estimate the rate of variation in blue-sky albedo, which is more appropriate for assessing the rate of variation in short or noisy time series [46]. The M-K and TS estimator nonparametric tests in this study were computed using the following equations:

$$
\begin{aligned}
& S=\sum_{k=1}^{n-1} \sum_{j=k+1}^{n} \operatorname{sgn}\left(X_{j}-X_{k}\right) \text {, where } j>k \\
& \operatorname{sgn}(x)= \begin{cases}1 & , x>0 \\
0 & , x=0 \\
-1 & , x<0\end{cases} \\
& \sigma^{2}=\frac{\left\{n(n-1)(2 n+5)-\sum_{j=1}^{p} t_{j}\left(t_{j}-1\right)\left(2 t_{j}+5\right)\right\}}{18} \\
& Z=\left\{\begin{array}{cc}
\frac{S-1}{\sigma}, & S>0 \\
0, & S=0 \\
\frac{S+1}{\sigma}, & S>0
\end{array}\right. \\
& T S=\operatorname{Median}\left(\frac{X_{j}-X_{k}}{t_{j}+t_{k}}\right)
\end{aligned}
$$

where $X_{j}$ and $X_{k}$ are the blue-sky albedo values in the $j$ th and $i$ th years, respectively. A positive value of TS indicates an increasing trend; otherwise, it indicates a decreasing trend. Test statistics $S$ and $Z$, shown in Equations (2) and (5), respectively, were used to determine significant variation by coupling with the two-tailed $\mathrm{Z}$ test. The null hypothesis $(\mathrm{H} 0)$ of the MK test, which is "no apparent trend" for the significance level of 0.05 , was used; H0 was rejected, and a significant trend was detected in the situation where the absolute value $\left|Z_{s}\right|>Z_{(1-\alpha / 2)}(\alpha$ is the confidence level, usually set to 0.01 or 0.05$)$.

\subsubsection{Partial Correlation Analysis}

Partial correlation coefficients were calculated to assess the dominant factor of bluesky albedo variation. Partial correlation analysis refers to the process of eliminating the influence of the third variable and only analyzing the correlation between the other two 
variables when two variables are simultaneously related to the third variable [47]. The partial correlation coefficient was calculated as follows:

$$
r_{i j \cdot h}=\frac{r_{i j}-r_{i h} r_{j h}}{\sqrt{\left(1-r_{i h}^{2}\right)\left(1-r_{j h}^{2}\right)}}
$$

where $r_{i j \cdot h}$ is the partial correlation coefficient between variables $i$ and $j$ after fixing variable $h ; r_{i j}, r_{i h}$ and $r_{j h}$ are the correlation coefficients between variables $i$ and $j, i$ and $h$ and $j$ and $h$, respectively:

$$
r_{i j \cdot h m}=\frac{r_{i j \cdot h}-r_{i m \cdot h} r_{j m \cdot h}}{\sqrt{\left(1-r_{i m \cdot h}^{2}\right)\left(1-r_{j m \cdot h}^{2}\right)}}
$$

where $r_{i j \cdot h m}$ is the partial correlation coefficient of variables $i$ and $j$ when the other variables are controlled, $r_{i m \cdot h}$ is the partial correlation coefficient between variables $i$ and $m$ after fixing variable $h$ and $r_{j m} \cdot h$ is the partial correlation coefficient between variables $j$ and $m$ after fixing variable $h$. In this study, variable $i$ stands for blue-sky albedo, and variables $j, h$ and $m$ stand for SC, SM and LAI, respectively.

\section{Results}

\subsection{Spatial Pattern of SC, SM, LAI and Blue-Sky Albedo}

Figure 2 displays the spatial pattern and statistics of the SC, SM, LAI and blue-sky albedo, computed as the 34 year average of the annual mean values during 1982-2015. The SC presented a clear latitudinal gradient, which gradually increased with increasing latitude. The SC was mainly distributed in the range of $0 \sim 100 \%$. The highest 34 year average SC was distributed in snow/ice and tundra, with a value higher than $65 \%$, followed by forest, grassland, barren land and cropland (Figure 2a). The SM was mainly distributed in the range of $0.01 \sim 0.75 \mathrm{~m}^{3} \mathrm{~m}^{-3}$. The highest 34 year average SM was distributed in snow/ice, forest and tundra, with values higher than $0.30 \mathrm{~m}^{3} \mathrm{~m}^{-3}$, followed by grassland, cropland, and barren land (Figure $2 b$ ). The LAI was mainly distributed in the range of 0.02-5.17. The highest 34 year average LAI was distributed in forest and cropland, with a value higher than 1.00, followed by grassland, tundra and barren land (Figure 2c). The blue-sky albedo was mainly distributed in the range of 0.02 0.80. The highest 34 year average blue-sky albedo was distributed in snow /ice and tundra, with values higher than 0.50 , followed by grassland, barren land, forest and cropland (Figure 2d).

\subsection{Trends in Annual Mean SC, SM, LAI, and Blue-Sky Albedo}

\subsubsection{Spatial Pattern of Trends}

Figure 3 displays the spatial pattern of annual mean trends in SC, SM, LAI and bluesky albedo in the middle-high latitudes of the NH $(p<0.05)$. Over the past 34 years, the annual mean SC of $23.73 \%$ of the total pixels had a significant change. Among those, $99.59 \%$ showed a significant decreasing trend, mainly concentrated in forest $(35.26 \%)$, tundra $(30.68 \%)$ and grassland $(24.02 \%)$, and the highest decrease rate was distributed in forest (Figure 3a). The annual mean SM of $22.27 \%$ of the total pixels had a significant trend, and $85.66 \%$ showed a significant decreasing trend, mainly concentrated in grassland $(32.50 \%)$, barren land (26.98\%) and forest (25.07\%). The highest decrease rate was distributed in forest and barren land. A total of $14.34 \%$ showed a significant increasing trend, mainly concentrated in barren land and forest (Figure 3b). For improving the estimation of SM in arid and semiarid areas, the self-calibrating palmer drought severity index (scPDSI) was selected as a supplement to verify the variation in SM (Figure S1). The results showed that the scPDSI in barren land was mainly decreasing, which was consistent with the SM results $[25,26]$. The annual mean LAI of $25.23 \%$ of the total pixels had a significant trend, and $74.38 \%$ showed a significant increasing trend, mainly concentrated in forest $(38.39 \%)$, barren land (23.66\%) and grassland (15.11\%). The highest increase rate was distributed 
in forest and cropland. A total of $25.62 \%$ showed a significant decreasing trend, mainly concentrated in barren land, forest and grassland (Figure 3c). The annual mean blue-sky albedo of $65.12 \%$ of the total pixels had a significant trend, and $98.97 \%$ of the annual mean blue-sky albedo showed a significant decreasing trend, mainly concentrated in forest $(22.80 \%)$, snow /ice $(17.73 \%)$, cropland $(17.73 \%)$ and barren land $(17.43 \%)$. The highest decrease rate was mainly distributed in snow/ice (Figure 3d).
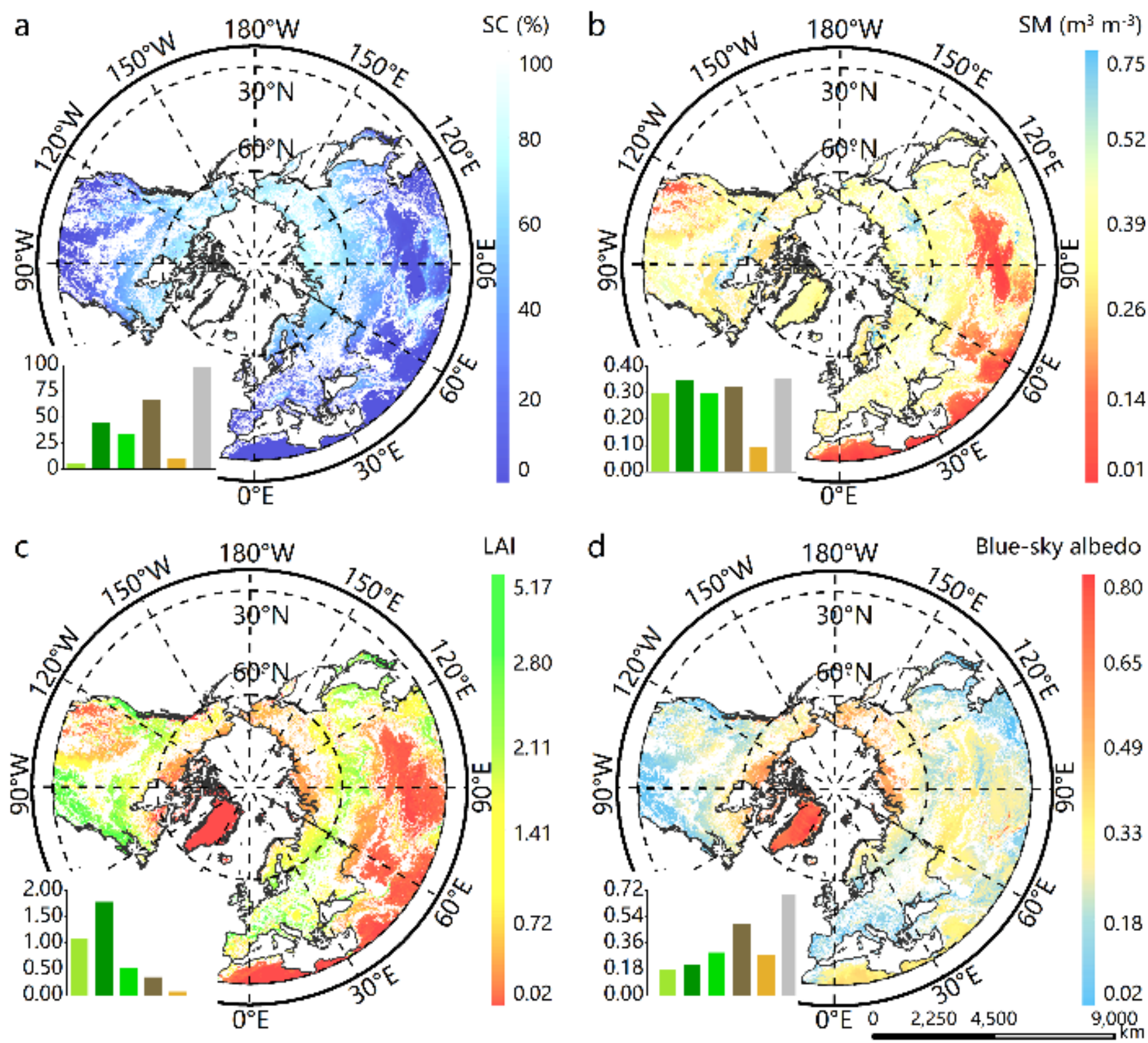

Figure 2. Spatial distribution of 34 year average SC (a), SM (b), LAI (c) and blue-sky albedo (d). Insets at the bottom left show the 34 year average of different land cover types in (a-d), with bar colors corresponding to the colors in the legend in the Figure 1a. 
a

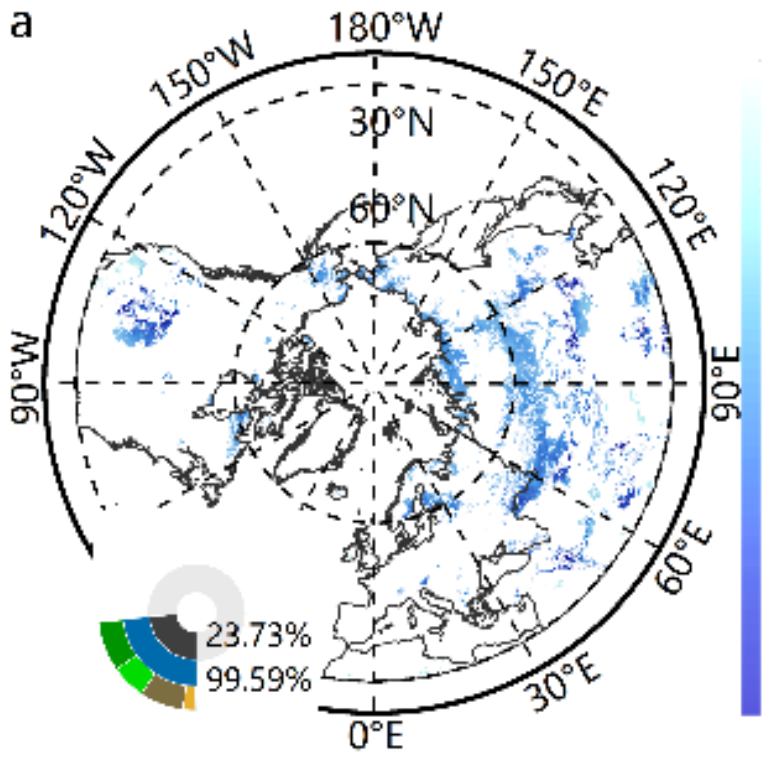

C

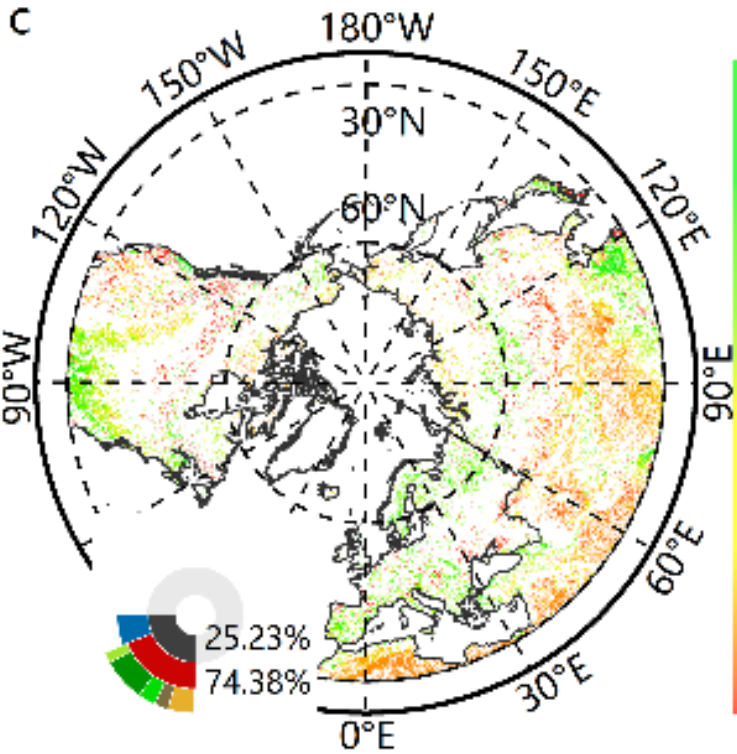

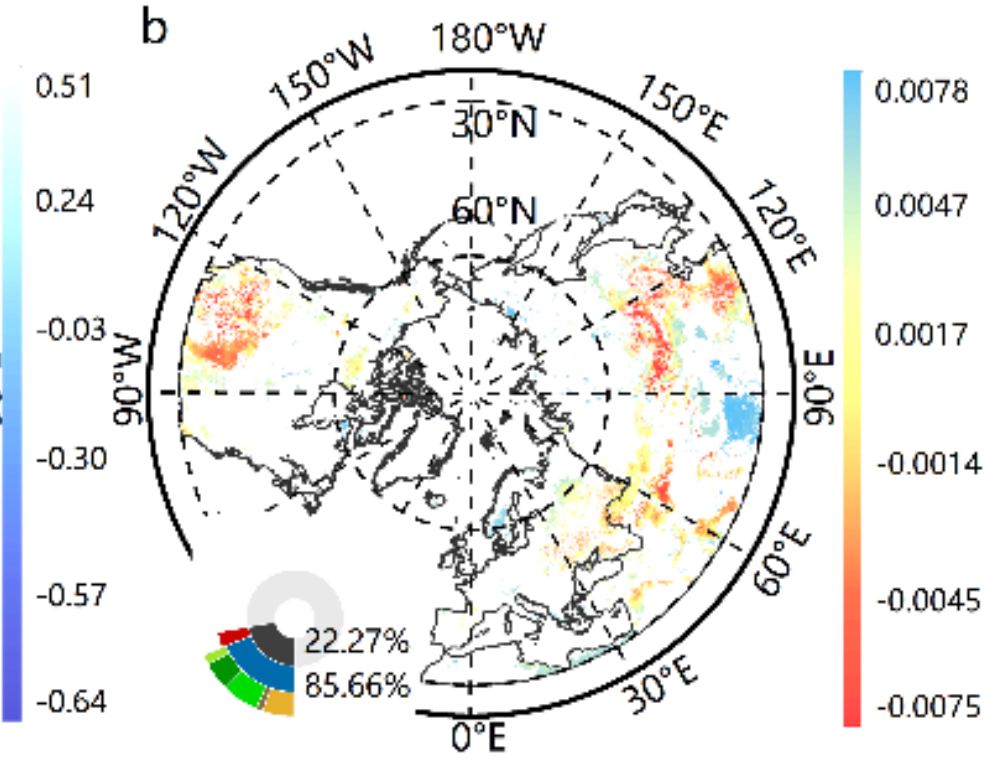

d

0.11

0.06

0.01

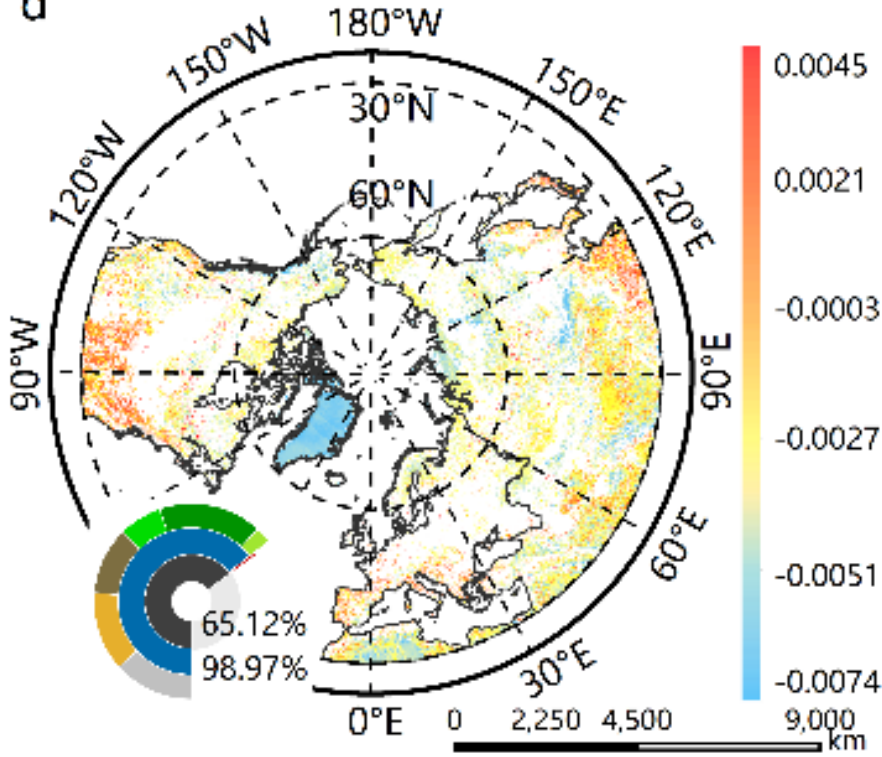

Figure 3. Spatial distribution of significant trends in annual mean SC (a), SM (b), LAI (c) and blue-sky albedo (d). Areas with $\mathrm{p}$ values higher than 0.05 are showed in white, and the colored regions are characterized by a $95 \%$ confidence interval. Insets at the bottom left show the percentages of pixels with a significant trend (dark gray), a significant increasing trend (red) and a significant decreasing trend (blue), respectively. Insets at the bottom left also show the percentages of pixels with a significant decreasing trend in $(\mathbf{a}, \mathbf{b}, \mathbf{d})$ in different land cover types, and the percentage of pixels with a significant increasing trend in (c) in different land cover types, with colors corresponding to the colors in the legend in the Figure 1a.

\subsubsection{Trends for Entire Study Area and Different Land Cover Types}

Figure 4 summarizes the interannual temporal variation trends of the average SC, SM, LAI and blue-sky albedo for the entire study area without consideration of land cover types and for different land cover types. Table 1 shows the fitting equation, goodness of fit and significance test ( $F$ test) of annual mean trends. 

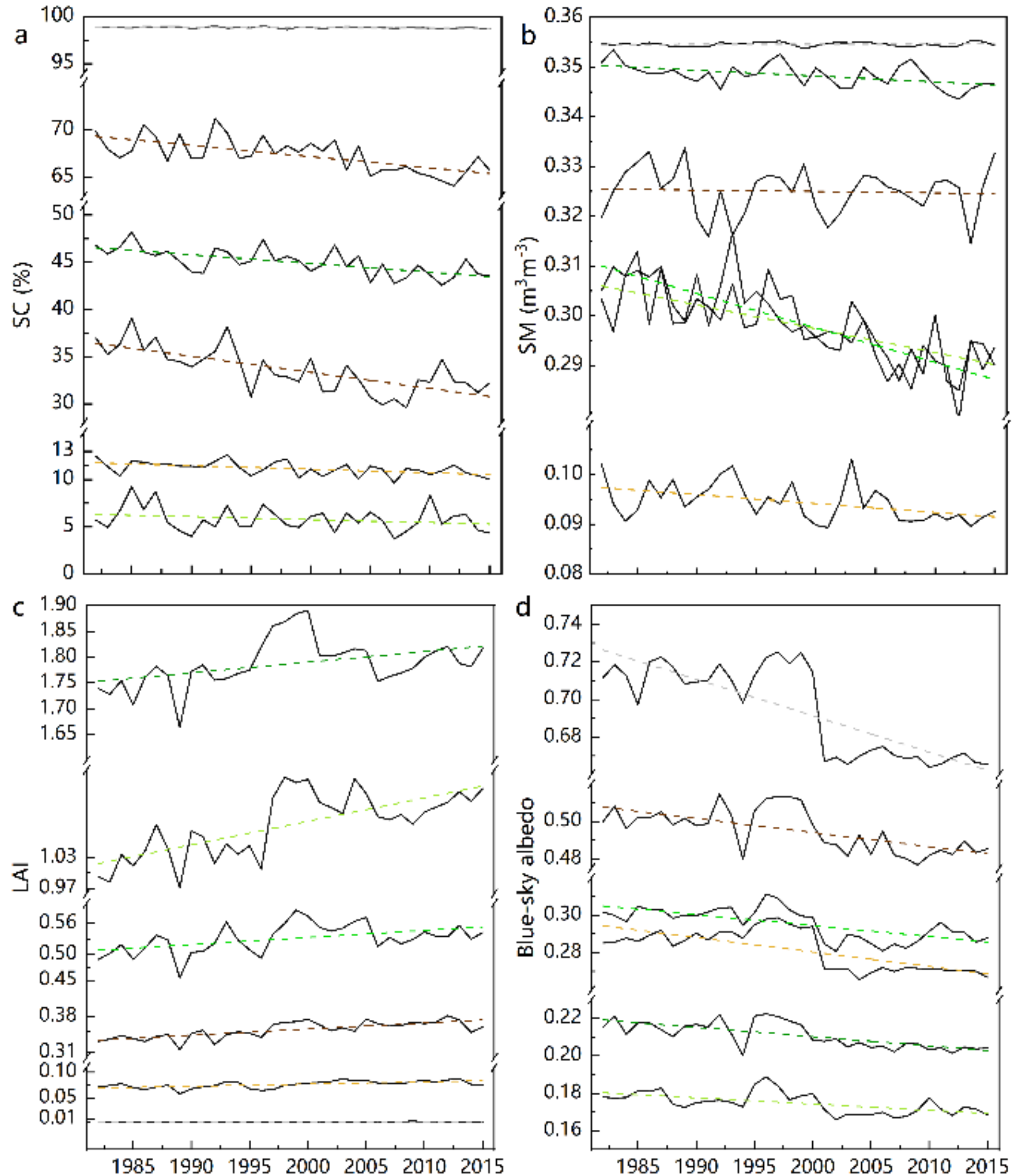

Figure 4. The trends of annual mean SC (a), SM (b), LAI (c) and blue-sky albedo (d) for the entire study area and different land cover types, with colors of fitting lines corresponding to the colors in the legend in the Figure 1a. 
Table 1. Summary of the fitting equation, goodness of fit, and significance test (F test) of annual mean trends of SC, SM, LAI and blue-sky albedo.

\begin{tabular}{|c|c|c|c|c|c|c|c|c|}
\hline & & cropland & forest & grassland & tundra & barren land & snow/ice & Entire study area \\
\hline SC & Fitting equation & $y=-0.3086 * x+6.3521$ & $\mathrm{y}=-0.9251 * \mathrm{x}+46.6361$ & $y=-1.7084 * x+36.5875$ & $\mathrm{y}=-1.1948 * \mathrm{x}+69.4468$ & $\mathrm{y}=-0.3765 * \mathrm{x}+11.8179$ & $\mathrm{y}=-0.0373 * \mathrm{x}+98.8814$ & $\mathrm{y}=-0.8125 * \mathrm{x}+48.2110$ \\
\hline SM & $\begin{array}{c}\text { Fitting equation } \\
R^{2}\end{array}$ & $y=-0.0048 * x+0.3065$ & $\mathrm{y}=-0.0012 * x+0.3505$ & $\mathrm{y}=-0.0069 * \mathrm{x}+0.3107$ & $\mathrm{y}=-0.0003 * \mathrm{x}+0.3255$ & $\mathrm{y}=-0.0018 * \mathrm{x}+0.0976$ & $\mathrm{y}=0.0001 * \mathrm{x}+0.3546$ & $\mathrm{y}=-0.0019 * \mathrm{x}+0.2939$ \\
\hline LAI & Fitting equation & $\mathrm{y}=0.0456 * \mathrm{x}+1.0135$ & $\mathrm{y}=0.0207 * \mathrm{x}+1.7512$ & $\mathrm{y}=0.0138 * \mathrm{x}+0.5070$ & $\mathrm{y}=0.0118 * \mathrm{x}+0.3331$ & $\mathrm{y}=0.0042 * \mathrm{x}+0.0692$ & $y=0.0004 * x+0.0033$ & $\begin{array}{c}\mathrm{y}=0.0136 * \mathrm{x}+0.7788 \\
0.3160^{* * *}\end{array}$ \\
\hline blue-sky albedo & $\begin{array}{c}\text { Fitting equation } \\
\mathrm{R}^{2}\end{array}$ & $y=-0.0033 * x+0.8315$ & $\begin{array}{c}\mathrm{y}=-0.0049 * \mathrm{x}+1.1950 \\
0.5069 * * *\end{array}$ & $\begin{array}{c}\mathrm{y}=-0.0058 * \mathrm{x}+1.4572 \\
0.4673 * * *\end{array}$ & $\begin{array}{c}\mathrm{y}=-0.0075 * \mathrm{x}+2.0020 \\
0.4265 * * *\end{array}$ & $\mathrm{y}=-0.0077 * \mathrm{x}+1.8290$ & $\mathrm{y}=-\begin{array}{c}0.0194 * \mathrm{x}+4.5791 \\
0.6544^{* * *}\end{array}$ & $\mathrm{y}=-0.0080 * \mathrm{x}+1.9152$ \\
\hline
\end{tabular}

Where, $x$ and $y$ represent the true and fitted values of SC, SM, LAI and blue-sky albedo, respectively. ${ }^{* *}$ Indicates a significant difference at $95 \%$ level, ${ }^{* * *}$ Indicates a significant difference at $99 \%$ level. The unit is decade ${ }^{-1}$. 
In term of the annual mean, the SC in the entire study area showed a significant decreasing trend, with a linear trend of -0.81 decade $^{-1}(p<0.01)$. The SC was distributed in the range of $44.97 \%$ to $48.93 \%$, with the maximum and minimum SC in 1983 and 1996, respectively. The SC of other land cover types, except cropland, showed obvious decreasing trends during the study period, with a linear trend of $-0.04 \sim-1.71$ decade $^{-1}(p<0.05)$. The SC of grassland and tundra was the highest (from $29.59 \%$ to $71.21 \%$ ), and the decrease rate of tundra was the second highest, which was -1.19 decade $^{-1}(p<0.01)$. The SC of cropland was the lowest (from $3.70 \%$ to $9.24 \%$ ), and its decreasing trend was not significant (Figure 4a, Table 1).

In terms of annual mean, the SM in the entire study area showed a significant decreasing trend, with a linear trend of $-0.19 \%$ decade $^{-1}(p<0.01)$. The SM was distributed in the range of 0.28 to $0.29 \mathrm{~m}^{3} \mathrm{~m}^{-3}$, with the maximum and minimum SM in 1987 and 2010, respectively. The SM of other land cover types, except snow /ice and tundra, consistently showed decreasing trends during the study period, with a linear trend of $-0.12 \% \sim-0.69 \%$ decade $^{-1}$ $(p<0.01)$. The SM of grassland and cropland was the highest (from 0.28 to $0.32 \mathrm{~m}^{3} \mathrm{~m}^{-3}$ ), and the decrease rate of cropland was the second highest, which was $-0.48 \%$ decade $^{-1}$ $(p<0.01)$. The SM of forest was the lowest (from 0.34 to $0.35 \mathrm{~m}^{3} \mathrm{~m}^{-3}$ ), and it had the lowest linear trend of $-0.12 \%$ decade $^{-1}(p<0.01)$. In particular, the SM of snow $/$ ice showed a nonsignificant increasing trend (Figure $4 \mathrm{~b}$, Table 1 ).

In terms of annual mean, the LAI in the entire study area showed a significant increasing trend, with a linear trend of $1.36 \%$ decade $^{-1}(p<0.01)$. The LAI was distributed in the range of 0.74 to 0.85 , with the maximum and minimum LAI in 2015 and 1982, respectively. The LAI for all land cover types consistently showed obvious increasing trends during the study period, with a linear trend of $0.04 \sim 4.56 \%$ decade $^{-1}(p<0.01)$. The LAI of cropland and forest was the highest (from 0.97 to 1.89), and the increase rate for forest was the second highest, which was $2.07 \%$ decade $^{-1}(p<0.01)$. The LAI of barren land was the lowest (from 0.003 to 0.005$)$, and its increase rate was the lowest, which was $0.04 \%$ decade $^{-1}(p<0.01$, Figure 4c, Table 1). The standard deviation and coefficient of variation of the fitting trend from 1982 to 2002 and from 2003 to 2015 were calculated, the results show that the LAI has entered a more stable period since 2003 (Table S1).

In terms of annual mean, the blue-sky albedo in the entire study area showed a significant decreasing trend, with a linear trend of $-0.80 \% \operatorname{decade}^{-1}(p<0.01)$. The bluesky albedo was distributed in the range from 0.33 to 0.36 , with the maximum and minimum blue-sky albedo in 1996 and 2007, respectively. Additionally, the blue-sky albedo for all selected land cover types consistently showed decreasing trends during the study period, with a linear trend of $-0.33 \sim-1.94 \%$ decade $^{-1}(p<0.01)$. The blue-sky albedo of snow /ice and barren land was the highest (from 0.27 to 0.73 ), and the decrease rate of barren land was the second highest, which was $-0.77 \%$ decade $^{-1}(p<0.01)$. The blue-sky albedo of cropland was the lowest (from 0.17 to 0.19 ), and its rate of decrease was the lowest, which was $-0.33 \%$ decade ${ }^{-1}(p<0.01$, Figure $4 d$, Table 1$)$. The standard deviation and coefficient of variation of the fitting trend from 1982 to 2002 and from 2003 to 2015 were calculated, the results show that the blue-sky albedo has entered a more stable period since 2003 (Table S2).

\subsection{Dominant Factor Analysis}

Figure 5 illustrates the spatial patterns and percentage of the partial correlation coefficients between the blue-sky albedo and three influencing factors of SC, SM and LAI at the 95\% confidence level. The results revealed that over the past 34 years, $57.01 \%$ of the study area had a significant correlation between the blue-sky albedo and SC, of which $98.16 \%$ had a significant positive correlation. The regions with partial correlation coefficients greater than 0.5 were mainly concentrated in tundra, grassland and forest. A total of $1.84 \%$ showed a significant negative correlation, and the regions with partial correlation coefficients lower than -0.5 were mainly concentrated in barren land and cropland (Figure 5a). A total of $17.13 \%$ of the study area had a significant correlation between the blue-sky albedo and $\mathrm{SM}$, of which $52.22 \%$ had a significant positive correlation. The regions with partial cor- 
relation coefficients greater than 0.5 were mainly concentrated in barren land, grassland and cropland. A total of $47.78 \%$ showed a significant negative correlation, and the regions with partial correlation coefficients lower than -0.5 were mainly concentrated in tundra, barren land and forest (Figure $5 \mathrm{~b}$ ). A total of $25.30 \%$ of the study area had a significant correlation between the blue-sky albedo and LAI, of which $32.62 \%$ had a significant positive correlation. The regions with partial correlation coefficients greater than 0.5 were mainly concentrated in barren land, grassland, forest and tundra. A total of $67.38 \%$ showed a significant negative correlation, and the regions with partial correlation coefficients lower than -0.5 were mainly concentrated in barren land, grassland, cropland and forest (Figure 5c).

a

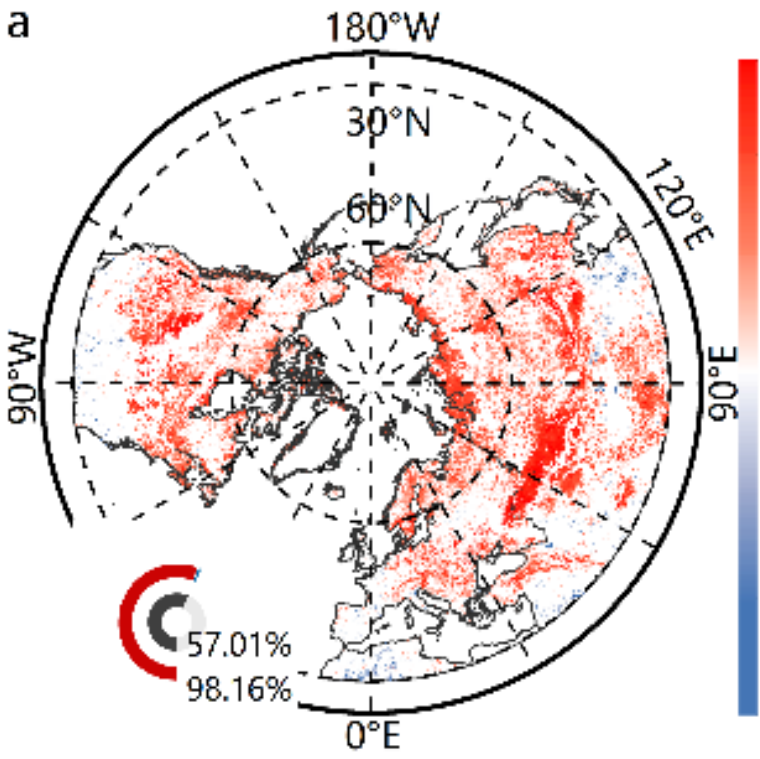

$C$

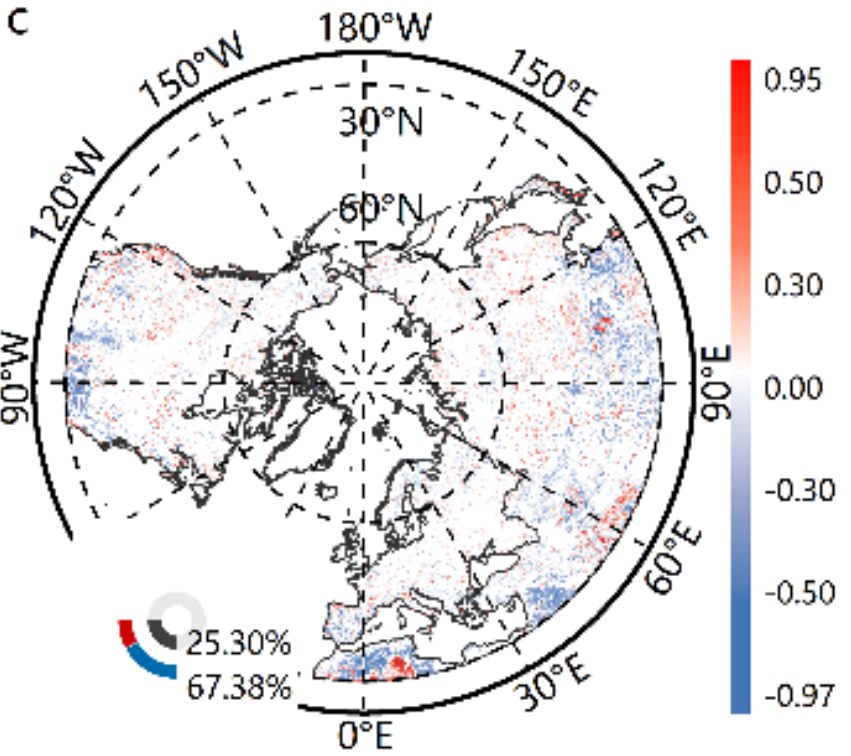

0.93

0.50

0.30

0.00

$-0.30$

$-0.50$

$-0.73$ b

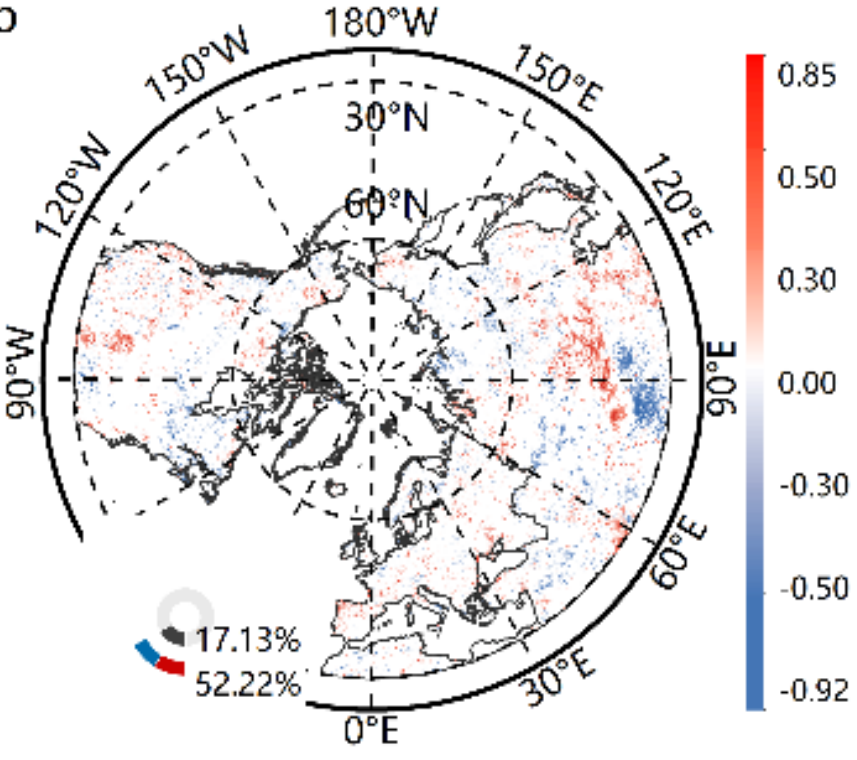

$d$

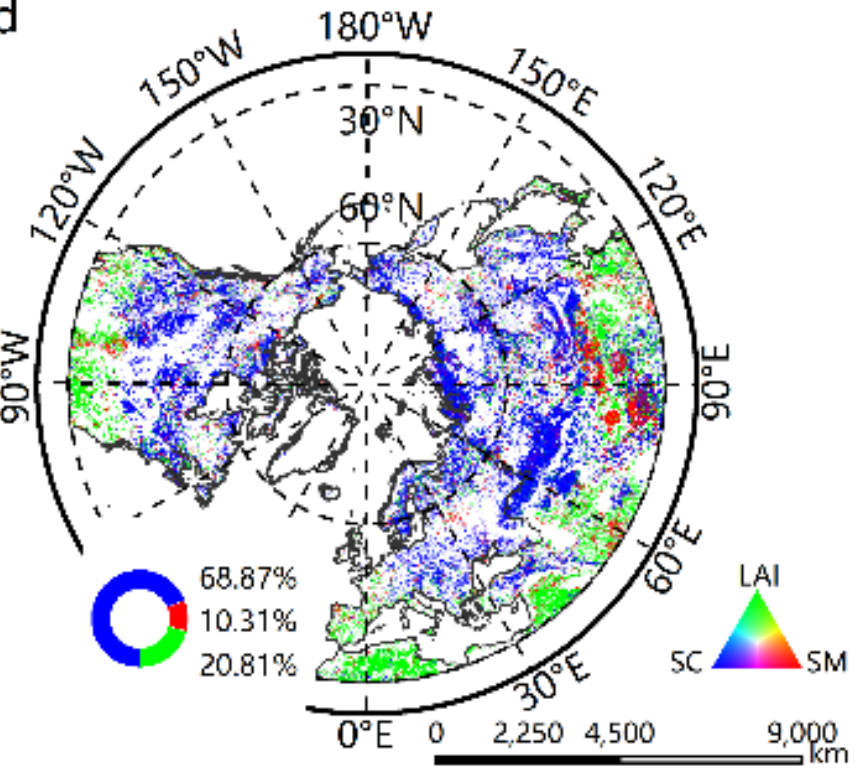

Figure 5. Spatial distributions of the partial correlation coefficients between blue-sky albedo and SC (a), SM (b) and LAI (c), the spatial distribution of RGB synthesis with three partial correlation coefficients (d). Nonsignificant pixels were excluded. Insets at the bottom left in $(\mathbf{a}-\mathbf{c})$ show the percentages of pixels with significant correlation (dark gray), significant positive correlation (red) and significant negative correlation (blue), respectively. Insets at the bottom left in (d) show the percentages of pixels dominated by each factor, with bar color corresponding to the color in the map. 
Figure $5 \mathrm{~d}$ displays the spatial distribution of RGB synthesis with partial correlation coefficients. The absolute values of the partial correlation coefficients of the three factors were assigned as red $(R)$, green $(G)$ and blue $(B)$, respectively, and the RGB composite map was generated. The dominant driving factors of blue-sky albedo in different regions can be directly judged through the color synthesis. Approximately $10.31 \%, 20.81 \%$ and $68.88 \%$ of the pixel blue-sky albedo reduction was mainly controlled by SC, SM and LAI, respectively. The SC-dominated regions were mainly concentrated in tundra, forest and grassland north of $40^{\circ} \mathrm{N}$, as well as grassland (e.g., Taurus Mountains), barren land (e.g., Hindu Kush Mountains, Tianshan Mountains and Altai Mountains) and cropland (e.g., Bode Plain and Northeast Plain) south of $40^{\circ} \mathrm{N}$. Many regions were jointly driven by SC and SM. The SM-dominated regions were mainly concentrated in barren land (e.g., Iran Plateau, Turan Plain, Tibetan Plateau, Tarim Basin, Turpan Basin and Mongolian Plateau), grassland (e.g., Mississippi Plain and Labrador Plateau) and tundra (e.g., Brooks Ridge and Northern Canada). The SM-dominated regions were scattered in forest and cropland, accounting for $6.02 \%$ and $6.23 \%$ of the total forest pixels and farmland pixels, respectively. The LAI-dominated regions were mainly concentrated in barren land (e.g., Colorado Plateau, Western Desert, Eastern Desert, Iran Plateau, Labrador Plateau, Tibetan Plateau, Turan Plain, Junggar Basin, Turpan Basin and Mongolian Plateau), grassland (e.g., Mississippi Plain and Tibetan Plateau), tundra (e.g., Brooks Ridge and Northern Canada) and cropland (e.g., Iberian Peninsula, Paris Basin, Pingning Peninsula and North China Plain). The LAI-dominated regions were scattered in forest, accounting for $11.76 \%$ of the total forest pixels. The regions jointly dominated by SM and LAI were mainly concentrated in barren land (e.g., Colorado Plateau, Western Desert, Eastern Desert, Iran Plateau, Turan Plain, Tibetan Plateau, Tarim Basin, Junggar Basin, Turpan Basin and Mongolian Plateau), forest (e.g., Eastern European Plain, Western Siberian Plain, Ardan Plain, Sikhote Mountains, Qinling Mountains and Japan), grassland (e.g., Mississippi Plain, Labrador Plateau, Taihang Mountains and Tibetan Plateau), tundra (e.g., Brooks Ridge and Northern Canada) and cropland (e.g., Iberian Peninsula, Paris Basin, Pingning Peninsula and North China Plain).

\section{Discussion}

\subsection{Spatiotemporal Variation in Blue-Sky Albedo}

Spatially, the 34 year average blue-sky albedo has obvious spatial heterogeneity. The highest blue-sky albedo was distributed in snow/ice and tundra, followed by grassland, barren land, forest and cropland (Figure 2d). These results were supported by the conclusions of other studies. For example, the LSA in Greenland was the highest, which was greater than 0.7, and increased with increasing altitude [48]. The blue-sky albedo of pixels with sparse vegetation cover (such as shrub and grassland) is often much higher than that of pixels with dense vegetation cover (such as forest) [49]. Inconsistent with other studies, the blue-sky albedo of grassland was slightly higher than that of barren land. By calculating the frequency of blue-sky albedo in the same range (Figure S2), the frequency of blue-sky albedo in grassland was the highest in the higher value range, while that in barren land was the highest in the lower value range. In addition, snowfall [50], overgrazing [51] and fire [52-54] have a great impact on the blue-sky albedo of grasslands, resulting in an increase in blue-sky albedo.

The results showed that the annual mean blue-sky albedo decreased from 0.3758 (1996) to 0.3460 (2007) during the past 34 years (Figure 4d), and it showed an obvious decreasing trend, with a slope of $0.80 \%$ decade $^{-1}(p<0.01$, Table 1$)$. The increasing trend was mainly observed in forests (Figure 3d). This result is consistent with previous research on LSA. For example, the LSA of NH decreased by 0.01 from 2000 to 2008 [34]. The LSA of high latitudes in the NH decreased by 0.013 from 2002 to 2016, while the LSA of low latitudes fluctuated little. The blue-sky albedo in Central Asia, Northeast China, some northern forests in Canada and temperate grasslands in North America showed an increasing trend from 2002 to 2016 [4]. White-sky albedo in northern North America, Central Europe, Central Asia and Northeast China showed an increasing trend from 1982 to 2015 [55]. There are 
three possible explanations for the higher reduction amplitude and rate of blue-sky albedo compared with other studies $[4,8,36,56]$. First, the blue-sky albedo was roughly estimated by using a fixed proportion of diffuse skylight $[57,58]$ or NCEP reanalysis data $[4,59]$ with coarser resolution, resulting in differences in the estimation of blue-sky albedo. Second, the MODIS albedo algorithm tended to generate snow-free albedo if most of the observations in the temporal combination were snow free, while the GLASS albedo product might contain albedo in transient snow, resulting in higher albedo than the MODIS product [60]. Third, the time scales were different, and this study only considered the stable land cover types. The decrease rate of blue-sky albedo in grassland $\left(0.58 \%\right.$ decade $\left.^{-1}\right)$ was higher than that in forest $\left(0.49 \%\right.$ decade $^{-1}$, Table 1$)$. There are two possible explanations for this finding. First, the species composition of grassland is simpler, the nutritional structure is simpler, the automatic regulation ability is lower and the resistance stability is lower compared with forest [61]. A total of $65.31 \%$ of forest and $36.52 \%$ of grassland have remained unchanged in the past 34 years, which also provided supporting evidence that the anti-interference ability of grassland was lower than that of forest (Figure 1b). Second, extreme climate [62], human settlement growth [63], desertification [64], fire [65], overgrazing [66] and alien species invasion [67] seriously affect the grassland surface, resulting in drastic variations in grassland blue-sky albedo.

\subsection{Dominant Factors of Blue-Sky Albedo}

A total of $98.16 \%$ of SC showed a significant positive correlation with blue-sky albedo, which was generally recognized (Figure $5 a$ ) $[4,56,68,69]$. With a decrease in the percentage of SC, the LSA decreased. The reason for the significant negative correlation between SC and blue-sky albedo may be that the snow albedo is affected by the total amount of snow [13], the number of snow days [13], the physical properties of snow [70] and the content of light absorbing impurities [70]. For example, fresh snow with small grains has a higher albedo, while aged snow has a lower albedo [13]. The albedo of polluted snow is lower than that of ordinary snow [70]. A total of $47.78 \%$ of SM showed a significant negative correlation with blue-sky albedo (Figure $5 b$ ), which was consistent with previous studies $[2,68,69]$. For example, when the soil changed from wet to dry, the color became brighter, which weakened the light absorption capacity of the surface and increased the LSA [71]. The following explanation may account for the significant positive correlation between SM and blue-sky albedo. First, in view of the hydrodynamic characteristics of soil, there was a critical point in the relationship curve between LSA and the soil surface; that is, when SM was lower than this critical point, LSA decreased with increasing SM. In contrast, when the SM was higher than this critical point, the LSA increased with increasing SM [72]. In humid and semi-humid tundra, forest and grassland, when SM was higher than this critical point, blue-sky albedo decreased with the decrease in SM. Second, some temperate forests and grasslands have high contents of soil organic matter (such as black soil and chernozem), deep colors, low reflectance in the visible band and small differences in reflectance between soil and vegetation [71]. The increase in blue-sky albedo caused by the decrease in SM was offset by the decrease in blue-sky albedo caused by the increase in LAI, which eventually led to the decrease in blue-sky albedo. Third, SM in barren land generally decreased, but mobile dunes and semimobile dunes greatly changed the surface, and the increase in surface roughness led to a decrease in blue-sky albedo [6]. A total of $67.38 \%$ of the LAI showed a significant negative correlation with blue-sky albedo (Figure 5c). Vegetation greening is known to cause a significant reduction in LSA $[4,68,69]$. The significant positive correlation between LAI and blue-sky albedo may be related to the increase in multiple scattering in the canopy with a relatively high LAI; with low LAI and canopy height, canopy development leads to an increase in scattering [73]. In some cases, LSA decreases with decreasing canopy coverage due to the relatively low soil reflectance [9]. In addition, litter and dead biomass have different spectral characteristics from green biomass and soil, which makes the relationship between greenness and LSA 
more complex [7]. In high-latitude forests and grasslands, the presence of snow shielded the vegetation surface and reduced the contribution of LAI to blue-sky albedo [74].

SC was considered to be the main driver of blue-sky albedo north of $40^{\circ} \mathrm{N}$ (Figure $5 \mathrm{~d}$ ). The correlation between LSA and SC in areas with coexisting snow and vegetation was stronger than that in snow-covered areas because the variation in vegetation might interact with the change in SC to adjust the feedback of snow albedo [75]. The presence of snow shielded the surface of soil and vegetation and reduced the contribution of LAI and SM to blue-sky albedo [74]. SM and LAI were considered to be the main drivers of blue-sky albedo south of $40^{\circ} \mathrm{N}$ (Figure 5d). The decrease in SM led to an increase in blue-sky albedo, and the greening of vegetation led to a decrease in blue-sky albedo, which offset each other. Vegetation structure (tree species structure, canopy structure, canopy height and forest age) [76] and soil properties (soil type, soil color, soil organic matter content and surface roughness) [71] also affect blue-sky albedo. For example, the deforestation of needleleaf trees showed a stronger increase in reflected radiation because needleleaf trees were usually darker than broadleaf trees [77]. The LSA decreased with increasing forest age under both summer and winter conditions [76]. With a higher soil organic matter content, deeper color or coarser soil, the soil albedo was lower [6]. The decrease in blue-sky albedo in the western Tibetan Plateau was caused by the decrease in SC, vegetation greening and the increase in SM. This phenomenon is consistent with previous studies [68,69]. From 1982 to 2015, the annual mean LSA of the Tibetan Plateau showed a slightly decreasing trend, with a rate of $-0.03 \%$ decade $^{-1}$. The LSA was positively correlated with SC and negatively correlated with NDVI and SM [68]. In general, the effects of SC, SM and LAI on blue-sky albedo were basically consistent with other studies. The difference is that some studies have pointed out that the greening trend in the high latitudes of the $\mathrm{NH}$ contributed more to the decrease in blue-sky albedo, and the violent fluctuation in SC in the middle latitudes dominated the variation in blue-sky albedo from 2002 to 2016 [4]. The possible reason is that the increase rate of LAI (1982-2015) was lower than that of NDVI (2002-2016), resulting in a greater contribution of SC to blue-sky albedo at high latitudes. The decrease in SC and vegetation greening in the middle latitudes reduced the contribution of SC to blue-sky albedo, while the contribution of vegetation to blue-sky albedo increased. In addition, vegetation greening can strengthen vegetation evapotranspiration and lead to regional water shortages and regional drought [77]. In arid and semiarid areas, the risk of flash drought increased significantly [78]. Our study further confirmed that SM was also one of the main drivers of blue-sky albedo in the middle latitudes.

\subsection{Limitations}

We also performed nonlinear fits to the temporal variation trends of SC, SM, LAI and blue-sky albedo (Figure S3). The fitting results of SC, LAI and blue-sky albedo were basically consistent with the linear fitting, while the fitting results of SM were quite different from the linear fitting. The SM of other land cover types except cropland and grassland showed a clear fluctuating trend during the study period [24,25], which was inconsistent with previous studies. This question is worth exploring. In the next work, we will discuss the difference between nonlinear fitting and linear fitting.

The correlation results between blue-sky albedo and factors may be affected by the uncertainty of data from different sources, such as satellite observation data used to estimate LSA and LAI. In addition, the long-term variation in ERA5 reanalysis data may be affected by the deviation related to the inhomogeneity of observation data in the assimilation system [79]. The uncertainty of ERA5 shortwave radiation, direct solar radiation and SM may affect the estimation of blue-sky albedo and the relationship between blue-sky albedo and SM.

In this study, we mainly focused on the blue-sky albedo variations caused by SC, SM and LAI, excluding other factors (topography, climate and soil type, etc.) $[6,8,10,71,76]$. The drivers of blue-sky albedo may vary in time and space, so finer temporal and spatial resolutions should be further explored to identify heterogeneous drivers. The spatiotemporal 
variation in stable land cover types of blue-sky albedo was analyzed only on the interannual scale. Some studies have pointed out that there were obvious seasonal differences in blue-sky albedo, and the changing land cover type might have a greater impact on blue-sky albedo [36]. Therefore, in the future, it is necessary to explore the spatiotemporal variation in blue-sky albedo with stable and changing land cover types on the seasonal scale, and consider comprehensive drivers.

\section{Conclusions}

In this study, we investigated the spatiotemporal variation in blue-sky albedo for stable land cover types in the middle-high latitudes of the NH from 1982 to 2015, and analyzed the main drivers affecting the blue-sky albedo of different land cover types. The main findings can be summarized as follows:

(1) The spatial distribution of the 34 year average SC, SM, LAI and blue-sky albedo exhibited distinct spatial heterogeneity. The highest SC occurred in snow/ice and tundra, which was higher than $65 \%$. The highest SM occurred in snow/ice, forest and tundra, which was higher than $0.30 \mathrm{~m}^{3} \mathrm{~m}^{-3}$. The highest LAI occurred in forest and cropland, which was higher than 1.00. The highest blue-sky albedo occurred in snow/ice and tundra, which was higher than 0.50. LAI and blue-sky albedo have entered a more stable period since 2003;

(2) SC, SM and blue-sky albedo exhibited decreasing trends in $99.59 \%, 85.66 \%$ and $98.97 \%$ of the total pixels, respectively (significantly in $23.73 \%, 22.27 \%$ and $65.12 \%$, respectively). LAI showed an increasing trend in $74.38 \%$ of the total pixels $(25.23 \%$ were significant). The SC of all land cover types except cropland showed a significant decreasing trend, and the decreasing rate of grassland was the highest $\left(1.71 \%\right.$ decade $\left.^{-1}\right)$. The SM of all land cover types except snow/ice and tundra showed a significant decreasing trend, and the decreasing rate of grassland was the highest $\left(0.69 \%\right.$ decade $\left.^{-1}\right)$. SM in tundra showed no significant increasing trend. The LAI of all land cover types showed a significant increasing trend, and the increasing rate of forest $\left(2.07 \%\right.$ decade $\left.^{-1}\right)$ was higher than that of grassland $\left(1.38 \%\right.$ decade $\left.^{-1}\right)$. The blue-sky albedo of all land cover types showed a significant decreasing trend, and the decreasing rate of grassland $\left(0.58 \%\right.$ decade $\left.^{-1}\right)$ was higher than that of forest $\left(0.49 \%\right.$ decade $\left.^{-1}\right)$;

(3) Spatially, approximately $98.16 \%$ of the total pixels (57.01\% significant) exhibited a positive correlation between blue-sky albedo and SC. Approximately $47.78 \%$ and $67.38 \%$ of the total pixels (17.13\% and $25.3 \%$ significant, respectively) exhibited negative correlations between blue-sky albedo and SM, blue-sky albedo and LAI, respectively. Approximately $10.31 \%, 20.81 \%$ and $68.88 \%$ of the pixel blue-sky albedo reduction was mainly controlled by SC, SM and LAI, respectively. Specifically, the decrease in blue-sky albedo north of $40^{\circ} \mathrm{N}$ was mainly caused by the decrease in SC, in which the decrease in blue-sky albedo in some tundra, forest and grassland was caused by the decrease in SC and SM, and the decrease in blue-sky albedo in sporadic forest and grassland was caused by SM reduction and vegetation greening. The decrease in blue-sky albedo south of $40^{\circ} \mathrm{N}$ was mainly caused by SM reduction and vegetation greening. However, the decrease in blue-sky albedo in the western Tibetan Plateau was caused by the decrease in SC, increase in SM and vegetation greening. The presence of mobile dunes and semimobile dunes in barren land greatly affected the surface and offset the increase in blue-sky albedo caused by SM reduction and vegetation browning.

Supplementary Materials: The following supporting information can be downloaded at: https: //www.mdpi.com/article/10.3390/rs14040895/s1, Table S1: Standard deviation and coefficient of variation of LAI fitting trend for different land cover types; Table S2: Standard deviation and coefficient of variation of blue-sky albedo fitting trend for different land cover types; Figure S1: Spatial distribution of significant trends in annual mean scPDSI $(p<0.05)$. Figure S2: The frequency distribution histogram of blue-sky albedo in grassland and barren land; Figure S3: The trends of annual mean SC (a), SM (b), LAI (c) and blue-sky albedo (d) for the entire study area and different land cover types, with colors of fitting lines corresponding to the colors in the legend in the Figure 1a. 
Author Contributions: All the authors of this manuscript have contributed substantially to the work reported. Conceptualization, S.Y., H.Z. (Hongyan Zhang), and Y.W.; methodology, S.Y., J.Z., and X.G.; software, S.Y., T.X., H.L., and H.Z. (Hang Zhao); validation, T.X., H.L., and H.Z. (Hang Zhao); writing-original draft preparation, S.Y.; writing—review and editing, S.Y., H.Z. (Hongyan Zhang), and Y.W. All supervision, H.Z. (Hongyan Zhang) and Y.W. All authors have read and agreed to the published version of the manuscript.

Funding: This research was funded by the National Natural Science Foundation of China (Grant No. 41771450, 41871330, 42071359, and 42171321), Foundation of the Education Department of Jilin Province (Grant No. JJKH20211291KJ), Science and Technology Development Plan of Jilin Province (Grant No. 20190103151JH) and the Fundamental Research Funds for the Central Universities (Grant No.2412019FZ002).

Data Availability Statement: No new data were created or analyzed in this study. Data sharing is not applicable to this article.

Acknowledgments: The authors would like to acknowledge the Center for Global Change Data Processing and Analysis of Beijing Normal University for providing GLASS AVHRR albedo product and GLASS AVHRR LAI product, PANGAEA for providing GLASS-GLC Product and European Centre for Medium-Range Weather Forecasts for providing ERA5 and ERA5-Land data.

Conflicts of Interest: The authors declare no conflict of interest.

\section{References}

1. Cess, R.D. Biosphere-albedo feedback and climate modeling. J. Atmos. Sci. 1978, 35, 1765-1768. [CrossRef]

2. Dickinson, R.E. Land Surface Processes and Climate-Surface Albedos and Energy Balance. Adv. Geophys. 1983, 25, $305-353$.

3. Ghimire, B.; Williams, C.A.; Masek, J.; Gao, F.; Wang, Z.S.; Schaaf, C.; He, T. Global albedo change and radiative cooling from anthropogenic land cover change, 1700 to 2005 based on MODIS, land use harmonization, radiative kernels, and reanalysis. Geophys. Res. Lett. 2014, 41, 9087-9096. [CrossRef]

4. Li, Q.; Ma, M.; Wu, X.; Yang, H. Snow Cover and Vegetation-Induced Decrease in Global Albedo From 2002 to 2016. J. Geophys. Res. Atmos. 2018, 123, 124-138. [CrossRef]

5. Zhang, W.; Furtado, K.; Wu, P.; Zhou, T.; Chadwick, R.; Marzin, C.; Rostron, J.; Sexton, D. Increasing precipitation variability on daily-to-multiyear time scales in a warmer world. Sci. Adv. 2021, 7. [CrossRef]

6. Zhang, Y.F.; Wang, X.P.; Rui, H.; Pan, Y.X.; Hao, Z. Variation of albedo to soil moisture for sand dunes and biological soil crusts in arid desert ecosystems. Environ. Earth Sci. 2014, 71, 1281-1288. [CrossRef]

7. Liu, F.S.; Chen, H.Y.; Shao, H.B. Albedo indicating land degradation around the Badain Jaran Desert for better land resources utilization. Sci. Total Environ. 2017, 578, 67-73. [CrossRef]

8. He, T.; Liang, S.; Song, D.-X. Analysis of global land surface albedo climatology and spatial-temporal variation during 1981-2010 from multiple satellite products. J. Geophys. Res. Atmos. 2014, 119, 10, 281-210, 298. [CrossRef]

9. Alessandri, A.; Catalano, F.; De Felice, M.; van den Hurk, B.; Balsamo, G. Varying snow and vegetation signatures of surface-albedo feedback on the Northern Hemisphere land warming. Environ. Res. Lett. 2021, 16, 034023. [CrossRef]

10. Riihela, A.; Manninen, T.; Laine, V. Observed changes in the albedo of the Arctic sea-ice zone for the period 1982-2009. Nat. Clim. Chang. 2013, 3, 895-898. [CrossRef]

11. Loranty, M.M.; Berner, L.T.; Goetz, S.J.; Jin, Y.; Randerson, J.T. Vegetation controls on northern high latitude snow-albedo feedback: Observations and CMIP5 model simulations. Glob Chang Biol 2014, 20, 594-606. [CrossRef]

12. Alibakhshi, S.; Hovi, A.; Rautiainen, M. Temporal dynamics of albedo and climate in the sparse forests of Zagros. Sci. Total Environ. 2019, 663, 596-609. [CrossRef] [PubMed]

13. Seidel, F.C.; Rittger, K.; Skiles, M.K.; Molotch, N.P.; Painter, T.H. Case study of spatial and temporal variability of snow cover, grain size, albedo and radiative forcing in the Sierra Nevada and Rocky Mountain snowpack derived from imaging spectroscopy. Cryosphere 2016, 10, 1229-1244. [CrossRef]

14. Hall, A.; Qu, X. What Controls the Strength of Snow-Albedo Feedback? J. Clim. 2007, 20, 3971-3981. [CrossRef]

15. Piao, S.; Wang, X.; Park, T.; Chen, C.; Lian, X.; He, Y.; Bjerke, J.W.; Chen, A.; Ciais, P.; Tømmervik, H.; et al. Characteristics, drivers and feedbacks of global greening. Nat. Rev. Earth Environ. 2019, 1, 14-27. [CrossRef]

16. Tuttle, S.; Salvucci, G. Empirical evidence of contrasting soil moisture-precipitation feedbacks across the United States. Science 2016, 52, 825-828. [CrossRef] [PubMed]

17. Kala, J.; Evans, J.P.; Pitman, A.J.; Schaaf, C.B.; Decker, M.; Carouge, C.; Mocko, D.; Sun, Q. Implementation of a soil albedo scheme in the CABLEv1.4b land surface model and evaluation against MODIS estimates over Australia. Geosci. Model Dev. 2014, 2014 7, 1671-1707. [CrossRef] 
18. Monitoring, A. Snow, Water, Ice and Permafrost in the Arctic (SWIPA); Summary for Policy-Makers. 2017. Available online: https:/ / www.amap.no/documents/doc/snow-water-ice-and-permafrost.-summary-for-policy-makers/1532 (accessed on 12 December 2021).

19. Robinson, D.A.; Frei, A. Seasonal variability of Northern Hemisphere snow extent using visible satellite data. Prof. Geogr. 2000, 52, 307-315. [CrossRef]

20. Thackeray, C.W.; Derksen, C.; Fletcher, C.G.; Hall, A. Snow and climate: Feedbacks, drivers, and indices of change. Curr. Clim. Chang. Rep. 2019, 5, 322-333. [CrossRef]

21. Flanner, M.G.; Shell, K.M.; Barlage, M.; Perovich, D.K.; Tschudi, M.A. Radiative forcing and albedo feedback from the Northern Hemisphere cryosphere between 1979 and 2008. Nat. Geosci. 2011, 4, 151-155. [CrossRef]

22. Lucht, W.; Prentice, I.C.; Myneni, R.B.; Sitch, S.; Friedlingstein, P.; Cramer, W.; Bousquet, P.; Buermann, W.; Smith, B. Climatic control of the high-latitude vegetation greening trend and Pinatubo effect. Science 2002, 296, 1687-1689. [CrossRef]

23. Zhu, Z.; Piao, S.; Myneni, R.B.; Huang, M.; Zeng, Z.; Canadell, J.G.; Ciais, P.; Sitch, S.; Friedlingstein, P.; Arneth, A.; et al. Greening of the Earth and its drivers. Nat. Clim. Chang. 2016, 6, 791-795. [CrossRef]

24. Jung, M.; Reichstein, M.; Ciais, P.; Seneviratne, S.I.; Sheffield, J.; Goulden, M.L.; Bonan, G.; Cescatti, A.; Chen, J.; De Jeu, R. Recent decline in the global land evapotranspiration trend due to limited moisture supply. Nature 2010, 467, 951-954. [CrossRef]

25. Deng, Y.; Wang, S.; Bai, X.; Luo, G.; Wu, L.; Cao, Y.; Li, H.; Li, C.; Yang, Y.; Hu, Z. Variation trend of global soil moisture and its cause analysis. Ecol. Indic. 2020, 110, 105939. [CrossRef]

26. McColl, K.A.; Alemohammad, S.H.; Akbar, R.; Konings, A.G.; Yueh, S.; Entekhabi, D. The global distribution and dynamics of surface soil moisture. Nat. Geosci. 2017, 10, 100-104. [CrossRef]

27. Zhou, S.; Williams, A.P.; Berg, A.M.; Cook, B.I.; Zhang, Y.; Hagemann, S.; Lorenz, R.; Seneviratne, S.I.; Gentine, P. Landatmosphere feedbacks exacerbate concurrent soil drought and atmospheric aridity. Proc. Natl. Acad. Sci. USA 2019, 116, 18848-18853. [CrossRef] [PubMed]

28. Feldman, A.F.; Short Gianotti, D.J.; Trigo, I.F.; Salvucci, G.D.; Entekhabi, D. Satellite-based assessment of land surface energy partitioning-soil moisture relationships and effects of confounding variables. Water Resour. Res. 2019, 55, 10657-10677. [CrossRef]

29. Donat, M.G.; Pitman, A.J.; Seneviratne, S.I. Regional warming of hot extremes accelerated by surface energy fluxes. Geophys. Res. Lett. 2017, 44, 7011-7019. [CrossRef]

30. Pulliainen, J.; Luojus, K.; Derksen, C.; Mudryk, L.; Lemmetyinen, J.; Salminen, M.; Ikonen, J.; Takala, M.; Cohen, J.; Smolander, T.; et al. Patterns and trends of Northern Hemisphere snow mass from 1980 to 2018 (vol 41, pg 861, 2020). Nature 2020, 582, E18. [CrossRef]

31. Ji, F.; Wu, Z.H.; Huang, J.P.; Chassignet, E.P. Evolution of land surface air temperature trend. Nat. Clim. Chang. 2014, 4, 462-466. [CrossRef]

32. Yla, B.; Yc, A.; Zhi, L.A. Dry/wet pattern changes in global dryland areas over the past six decades. Glob. Planet. Chang. 2019, 178, 184-192.

33. Xu, X.Y.; Riley, W.J.; Koven, C.D.; Jia, G.S.; Zhang, X.Y. Earlier leaf-out warms air in the north. Nat. Clim. Chang. 2020, 10, 370. [CrossRef]

34. Zhang, X.T.; Liang, S.L.; Wang, K.C.; Li, L.; Gui, S. Analysis of Global Land Surface Shortwave Broadband Albedo From Multiple Data Sources. IEEE J. Sel. Top. Appl. Earth Obs. Remote Sensin 2010, 3, 296-305. [CrossRef]

35. Zhao, X.; Liang, S.; Liu, S.; Yuan, W.; Xiao, Z.; Liu, Q.; Cheng, J.; Zhang, X.; Tang, H.; Zhang, X.; et al. The Global Land Surface Satellite (GLASS) Remote Sensing Data Processing System and Products. Remote Sens. 2013, 5, 2436-2450. [CrossRef]

36. Chrysoulakis, N.; Mitraka, Z.; Gorelick, N. Exploiting satellite observations for global surface albedo trends monitoring. Theor. Appl. Climatol. 2018, 137, 1171-1179. [CrossRef]

37. Stephens, G.L.; O’Brien, D.; Webster, P.J.; Pilewski, P.; Kato, S.; Li, J.1. The albedo of Earth. Rev. Geophys. 2015, 53, 141-163. [CrossRef]

38. Román, M.O.; Schaaf, C.B.; Lewis, P.; Gao, F.; Anderson, G.P.; Privette, J.L.; Strahler, A.H.; Woodcock, C.E.; Barnsley, M. Assessing the coupling between surface albedo derived from MODIS and the fraction of diffuse skylight over spatially-characterized landscapes. Remote Sens. Environ. 2010, 114, 738-760. [CrossRef]

39. Xiao, Z.; Liang, S.; Jiang, B. Evaluation of four long time-series global leaf area index products. Agric. For. Meteorol. 2017, 246, 218-230. [CrossRef]

40. Liu, H.; Gong, P.; Wang, J.; Clinton, N.; Bai, Y.Q.; Liang, S.L. Annual dynamics of global land cover and its long-term changes from 1982 to 2015. Earth Syst. Sci. Data 2020, 12, 1217-1243. [CrossRef]

41. Hersbach, H.; Bell, B.; Berrisford, P.; Hirahara, S.; Horányi, A.; Muñoz-Sabater, J.; Nicolas, J.; Peubey, C.; Radu, R.; Schepers, D.; et al. The ERA5 global reanalysis. Q. J. R. Meteorol. Soc. 2020, 146, 1999-2049. [CrossRef]

42. Muñoz-Sabater, J.; Dutra, E.; Agustí-Panareda, A.; Albergel, C.; Arduini, G.; Balsamo, G.; Boussetta, S.; Choulga, M.; Harrigan, S.; Hersbach, H. ERA5-Land: A state-of-the-art global reanalysis dataset for land applications. Earth Syst. Sci. Data Discuss. 2021, 13, 4349-4383. [CrossRef]

43. Jackson, R.B.; Canadell, J.G.; Ehleringer, J.R.; Mooney, H.A.; Schulze, E. A Global Analysis of Root Distributions for Terrestrial Biomes. Oecologia 1996, 108, 389-411. [CrossRef]

44. Qiu, J.; Crow, W.T.; Nearing, G.S.; Mo, X.; Liu, S. The impact of vertical measurement depth on the information content of soil moisture times series data. Geophys. Res. Lett. 2015, 41, 4997-5004. [CrossRef] 
45. Sen, Z. Innovative Trend Analysis Methodology. J. Hydrol. Eng. 2012, 17, 1042-1046. [CrossRef]

46. Fernandes, R.; Leblanc, S.G. Parametric (modified least squares) and non-parametric (Theil-Sen) linear regressions for predicting biophysical parameters in the presence of measurement errors. Remote Sens. Environ. 2005, 95, 303-316. [CrossRef]

47. Brown, B.L.; Hendrix, S.B. Partial Correlation Coefficients; American Cancer Society: Atlanta, GA, USA, 2005.

48. Moustafa, S.E.; Rennermalm, A.K.; Román, M.O.; Wang, Z.; Schaaf, C.B.; Smith, L.C.; Koenig, L.S.; Erb, A. Evaluation of satellite remote sensing albedo retrievals over the ablation area of the southwestern Greenland ice sheet. Remote Sens. Environ. 2017, 198, 115-125. [CrossRef]

49. Tian, L.; Zhang, Y.; Zhu, J. Decreased surface albedo driven by denser vegetation on the Tibetan Plateau. Environ. Res. Lett. 2014, 9, 104001. [CrossRef]

50. Wang, S.; Davidson, A. Impact of climate variations on surface albedo of a temperate grassland. Agric. For. Meteorol. 2007, 142, 133-142. [CrossRef]

51. Li, S.G.; Harazono, Y.; Oikawa, T.; Zhao, H.L.; He, Z.Y.; Chang, X.L. Grassland desertification by grazing and the resulting micrometeorological changes in Inner Mongolia. Agric. For. Meteorol. 2000, 102, 125-137.

52. Liu, Y.; Hao, X.; Qu, J.J. Climate Impacts of Fire-Induced Land-Surface Changes. In Proceedings of the AGU Fall Meeting Abstracts, New Orleans, LA, USA, 11-15 December 2017; New Orleans Morial Convention Center: New Orleans, LA, USA, 2017; p. GC51B-0806.

53. Mota, B.; Gobron, N.; Cappucci, F.; Morgan, O. Burned area and surface albedo products: Assessment of change consistency at global scale. Remote Sens. Environ. 2019, 225, 249-266. [CrossRef]

54. Saha, M.V.; D’Odorico, P.; Scanlon, T.M. Kalahari Wildfires Drive Continental Post-Fire Brightening in Sub-Saharan Africa. Remote Sens. 2019, 11, 1090. [CrossRef]

55. Li, X.; Qu, Y.; Lv, M.; Song, Y.; Zhao, X. The Driving Factors of Global Land Surface Albedo: An Analysis with the Glass and Merra-2 Data. In Proceedings of the 2021 IEEE International Geoscience and Remote Sensing Symposium IGARSS, Brussels, Belgium, 11-16 July 2021; pp. 6661-6664.

56. Lin, X.W.; Wen, J.G.; Liu, Q.H.; You, D.Q.; Wu, S.B.; Hao, D.L.; Xiao, Q.; Zhang, Z.Y.; Zhang, Z.Z. Spatiotemporal Variability of Land Surface Albedo over the Tibet Plateau from 2001 to 2019. Remote Sens. 2020, 12, 1188. [CrossRef]

57. Li, Y.; Zhao, M.; Motesharrei, S.; Mu, Q.; Kalnay, E.; Li, S. Local cooling and warming effects of forests based on satellite observations. Nat. Commun. 2015, 6, 1-8. [CrossRef] [PubMed]

58. Ma, W.; Jia, G.; Zhang, A. Multiple satellite-based analysis reveals complex climate effects of temperate forests and related energy budget. J. Geophys. Res. Atmos. 2017, 122, 3806-3820. [CrossRef]

59. Liang, S.; Wang, K.; Zhang, X.; Wild, M. Review on estimation of land surface radiation and energy budgets from ground measurement, remote sensing and model simulations. IEEE J. Sel. Top. Appl. Earth Obs. Remote Sens. 2010, 3, 225-240. [CrossRef]

60. Liu, Q.; Wang, L.; Qu, Y.; Liu, N.; Liu, S.; Tang, H.; Liang, S. Preliminary evaluation of the long-term GLASS albedo product. Int. J. Digit. Earth 2013, 6, 69-95. [CrossRef]

61. Isbell, F.; Craven, D.; Connolly, J.; Loreau, M.; Schmid, B.; Beierkuhnlein, C.; Bezemer, T.M.; Bonin, C.; Bruelheide, H.; Luca, E.D. Biodiversity increases the resistance of ecosystem productivity to climate extremes. Nature 2015, 526, 574-577. [CrossRef]

62. Felton, A.J.; Slette, I.J.; Smith, M.; Knapp, A.K. Precipitation amount and event size interact to reduce ecosystem functioning during dry years in a mesic grassland. Glob. Chang. Biol. 2020, 26, 658-668. [CrossRef]

63. Zheng, K.; Wei, J.Z.; Pei, J.Y.; Cheng, H.; Zhang, X.L.; Huang, F.Q.; Li, F.M.; Ye, J.S. Impacts of climate change and human activities on grassland vegetation variation in the Chinese Loess Plateau. Sci. Total Environ. 2019, 660, 236-244. [CrossRef]

64. Na, R.; Du, H.; Na, L.; Shan, Y.; Huang, L. Spatiotemporal changes in the Aeolian desertification of Hulunbuir Grassland and its driving factors in China during 1980-2015. Catena 2019, 182, 658-668. [CrossRef]

65. Krb, A.; Snk, A.; Kmf, A.; La, B.; Ah, B. Characterizing grassland fire activity in the Flint Hills region and air quality using satellite and routine surface monitor data-ScienceDirect. Sci. Total Environ. 2019, 659, 1555-1566.

66. Wei, D.; Zhao, H.; Zhang, J.; Qi, Y.; Wang, X. Human activities alter response of alpine grasslands on Tibetan Plateau to climate change. J. Environ. Manag. 2020, 262, 110335.110331-110335.110338. [CrossRef] [PubMed]

67. Lazzaro, L.; Bolpagni, R.; Buffa, G.; Gentili, R.; Lastrucci, L. Impact of invasive alien plants on native plant communities and Natura 2000 habitats: State of the art, gap analysis and perspectives in Italy. J. Environ. Manag. 2020, 274, 111140. [CrossRef] [PubMed]

68. Pang, G.; Chen, D.; Wang, X.; Lai, H.-W. Spatiotemporal variations of land surface albedo and associated influencing factors on the Tibetan Plateau. Sci. Total Environ. 2022, 804. [CrossRef] [PubMed]

69. Zheng, L.; Qi, Y.; Qin, Z.; Xu, X.; Dong, J. Assessing albedo dynamics and its environmental controls of grasslands over the Tibetan Plateau. Agric. For. Meteorol. 2021, 307. [CrossRef]

70. Thakur, R.C.; Arun, B.S.; Gogoi, M.M.; Thamban, M.; Tha Yy En, R.J.; Redkar, B.L.; Babu, S.S. Multi-layer distribution of Black Carbon and Inorganic Ions in the Snow-packs of western Himalayas and Snow Albedo Forcing-ScienceDirect. Atmos. Environ. 2021, 261, 118564. [CrossRef]

71. Post, D.F.; Fimbres, A.; Matthias, A.D.; Sano, E.E.; Accioly, L.; Batchily, A.K.; Ferreira, L.G. Predicting Soil Albedo from Soil Color and Spectral Reflectance Data. Soil Sci. Soc. Am. J. 2000, 64, 1027-1034. [CrossRef]

72. Liu, W.; Baret, F.; Gu, X.; Tong, Q.; Zheng, L.; Zhang, B. Relating soil surface moisture to reflectance. Remote Sens. Environ. 2002, $81,238-246$ 
73. Taaa, B.; Jha, B.; Ppa, B.; Mrc, D.; Eem, A. Clarifying the role of radiative mechanisms in the spatio-temporal changes of land surface temperature across the Horn of Africa. Remote Sens. Environ. 2019, 221, 210-224.

74. Webster, C.; Jonas, T. Influence of canopy shading and snow coverage on effective albedo in a snow-dominated evergreen needleleaf forest. Remote Sens. Environ. 2018, 214, 48-58. [CrossRef]

75. Euskirchen, E.S.; Bennett, A.P.; Breen, A.L.; Genet, H.; Lindgren, M.A.; Kurkowski, T.A.; Mcguire, A.D.; Rupp, T.S. Consequences of changes in vegetation and snow cover for climate feedbacks in Alaska and northwest Canada. Environ. Res. Lett. 2016, 11, 105003. [CrossRef]

76. Amiro, B.D.; Orchansky, A.L.; Barr, A.G.; Black, T.A.; Randerson, J.T. The effect of post-fire stand age on the boreal forest energy balance. Agric. For. Meteorol. 2006, 140, 41-50. [CrossRef]

77. Duveiller, G.; Hooker, J.; Cescatti, A. The mark of vegetation change on Earth's surface energy balance. Nat. Commun. 2018, 9, 679. [CrossRef] [PubMed]

78. Yuan, X.; Wang, L.; Wu, P.; Ji, P.; Sheffield, J.; Zhang, M. Anthropogenic shift towards higher risk of flash drought over China. Nat. Commun. 2019, 10, 1-8. [CrossRef] [PubMed]

79. Li, M.; Wu, P.; Ma, Z. A comprehensive evaluation of soil moisture and soil temperature from third-generation atmospheric and land reanalysis data sets. Int. J. Climatol. 2020, 40, 5744-5766. [CrossRef] 